\title{
Hydrothermal Synthesis of Platinum Group Metal Nanoparticles
}

\author{
Stjepko Krehula* and Svetozar Musić \\ Division of Materials Chemistry, Ruđer Bošković Institute, P.O. Box 180, HR-10002 Zagreb, Croatia \\ RECEIVED JANUARY 27, 2011; REVISED MARCH 31, 2011; ACCEPTED APRIL 20, 2011
}

\begin{abstract}
A novel route for the synthesis of platinum group metal nanoparticles has been reported. The synthesis is based on the addition of tetramethylammonium hydroxide (TMAH) to the aqueous $\mathrm{PtCl}_{4}$, $\mathrm{IrCl}_{3}$ or $\mathrm{Rh}\left(\mathrm{NO}_{3}\right)_{3}$ solution followed by the hydrothermal treatment of these precipitation systems at $160{ }^{\circ} \mathrm{C}$. The mean size of nanoparticles was $9.2 \mathrm{~nm}$ for platinum, $21 \mathrm{~nm}$ for iridium, and $28 \mathrm{~nm}$ for rhodium. The average crystallite size was estimated at $7.4 \mathrm{~nm}$ for platinum, $3.1 \mathrm{~nm}$ for iridium and $3.5 \mathrm{~nm}$ for rhodium. The possible mechanism of platinum group metal nanoparticles formation is briefly discussed. (doi: 10.5562/cca1856)
\end{abstract}

Keywords: platinum, iridium, rhodium, nanoparticles, hydrothermal synthesis, tetramethylammonium hydroxide

\section{INTRODUCTION}

Platinum group metals are essential elements in modern technology, owing to their outstanding catalytic properties. Their utilization involves catalytic converters for catalytic control of car exhaust emissions, jewellery and watchmaking, chemical and petroleum refining industry (superb catalysts), electronics (hard drives), fuel cells (also as catalysts), liquid crystal display (LCD) glass and other glasses, anticancer drugs, spark plugs, electrodes, sensors, turbine engine coatings, medical components, dental alloys etc. ${ }^{1-3}$

The use of platinum group metals as catalysts requires the largest possible active surface with an aim to provide a maximum possible number of catalytically active sites. A high surface area relative to volume ratio is obtained by using metal particles in the nanometer range as a catalytically active substance, either suspended in a reaction solution (quasi-homogeneous catalysis) or deposited on a particular support (heterogeneous catalysis). ${ }^{4}$ Dispersed and supported platinum group metal nanoparticles are used in the catalysis of a broad range of reactions: fuel-cell reactions, electrontransfer reactions, hydrogenations, oxidations, decomposition reactions, etc. ${ }^{5,6}$

The most common method used to synthesize platinum group metal nanoparticles is chemical reduction in a solution using hydrogen gas, ${ }^{7-13}$ alcohols, ${ }^{14-20}$ ethylene glycol, ${ }^{21}$ various hydrides ${ }^{22-24}$ or other reducing agents. ${ }^{25,26}$ Platinum group metal nanoparticles can also be produced by electrochemical reduction, ${ }^{27,28}$ laser ablation of a platinum metal plate, ${ }^{29}$ microemulsion method, ${ }^{30}$ aerosol assisted deposition method ${ }^{31}$ or partial dissolution of Au-Pt nanoalloys. ${ }^{32}$

In our previous work ${ }^{33}$ we reported on a novel route for the synthesis of the nanosize particles of metallic palladium based on the precipitation of palladium hydroxide or oxide particles with tetramethylammonium hydroxide (TMAH) at high $\mathrm{pH}$ value followed by the hydrothermal processing of the suspensions obtained. In the present work we have expanded our investigation on the possibility of preparing the nanosize particles of metallic platinum, iridium and rhodium by the proposed method.

\section{EXPERIMENTAL}

\section{Sample Preparation}

The platinum(IV) chloride solution ( $w=5 \%$ ) supplied by Hopkin \& Williams Ltd., the iridium(III) chloride hydrate, $99.9 \%$ (metal basis) supplied by Alfa Aesar ${ }^{\circledR}$, the rhodium(III) nitrate solution, $w(\mathrm{Rh}) \approx 10 \%$ in $\mathrm{HNO}_{3}$ $\left(w\left(\mathrm{HNO}_{3}\right)=20-25 \%\right)$ supplied by Acros Organics, the TMAH solution $(w($ TMAH $)=25 \%)$, electronic grade $99.9999 \%$ ) supplied by Alfa Aesar ${ }^{\mathbb{B}}$ and twice-distilled water prepared in our own laboratory, were used. The above metal salts were dissolved in twice-distilled water. The quantity of $10 \mathrm{ml}$ of TMAH solution as received was added to achieve the alkaline $\mathrm{pH}$ value. The

\footnotetext{
* Author to whom correspondence should be addressed. (E-mail: krehul@irb.hr)
} 
final concentrations of ions in precipitation systems were $0.018 \mathrm{~mol} \mathrm{dm}^{-3}$ for platinum ions, $0.040 \mathrm{~mol} \mathrm{dm}^{-3}$ for iridium ions and $0.017 \mathrm{~mol} \mathrm{dm}^{-3}$ for rhodium ions. These molar concentrations were chosen in order to create suitable conditions for the formation of homogenous suspensions of metal hydroxides or oxides and at the same time a large enough quantity of the final products for the recording of good quality XRD powder patterns. The suspensions thus formed were vigorously shaken for about $10 \mathrm{~min}$, then heated at $160^{\circ} \mathrm{C}$ for 24 hours, using the Parr general-purpose bomb (model 4744), comprising a Teflon vessel and a cup. The precipitates were cooled to $\mathrm{RT}$ (mother liquor $\mathrm{pH} \approx 13.5$ ) and subsequently washed with twice-distilled water and ethanol to remove the "neutral electrolyte". The ultraspeed Sorvall RC2-B centrifuge was used. After drying the precipitates were characterized by X-ray powder diffraction (XRD) and field-emission scanning electron microscopy (FE-SEM).

\section{Characterization}

X-ray powder diffractometer APD $2000(\mathrm{Cu}-\mathrm{K} \alpha$ radiation, graphite monochromator, NaI-Tl detector) manufactured by ItalStructures (Riva Del Garda, Italy) was used. The full width at half maximum (FWHM) value of the (111) diffraction line was obtained by fitting a pseudo-Voigt function to experimental data using the WinDust32 program (ItalStructures). The mean crystallite dimension (MCD) in the [111] crystallographic direction was estimated from the line broadening of the (111) diffraction line using the Scherrer equation, after correcting the measured full width at half maximum (FWHM) for instrumental broadening.

A JEOL thermal field emission scanning electron microscope (FE-SEM, model JSM-7000F) was used.

\section{RESULTS AND DISCUSSION}

X-ray powder diffraction patterns of the prepared samples are shown in Figure 1. These XRD patterns correspond to metallic platinum (JCPDS PDF card No. 040802), iridium (JCPDS PDF card No. 06-0598) and rhodium (JCPDS PDF card No. 05-0685). All these phases crystallize in the cubic crystal system (space group Fm-3m, $a=3.9231 \AA$ for platinum, $a=3.8394 \AA$ for iridium and $a=3.8031 \AA$ for rhodium). A significant broadening of diffraction lines can be taken as a sign of very small crystallites and of a certain amount of noncrystalline material. The average crystallite size was estimated at $c a .7 .4 \mathrm{~nm}$ for platinum, $3.1 \mathrm{~nm}$ for iridium and $3.5 \mathrm{~nm}$ for rhodium from the FWHM value of the diffraction line (111) by using the Scherrer equation. The larger crystallite size of platinum nanoparticles in comparison with rhodium and iridium samples can be explained by the formation of a smaller number of pla-

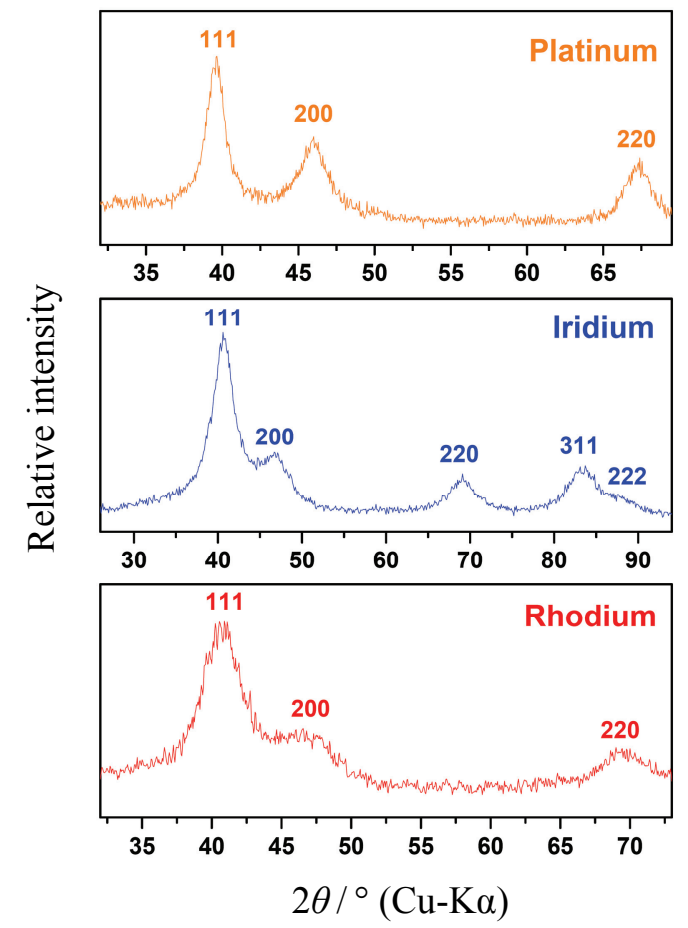

Figure 1. XRD patterns of platinum, iridium and rhodium nanoparticles. A significant broadening of diffraction lines is noticeable.

tinum nuclei in the initial stage of the process of nanoparticle formation by metal cations reduction.

FE-SEM images obtained at lower magnification show that the platinum sample consists of irregular aggregates (Figure 2a), while the iridium sample consists of fairly uniform pseudospherical aggregates of about 200-500 $\mathrm{nm}$ in diameter. (Figure 2c). Highermagnification FE-SEM images of the platinum (Figure 2b) and iridium samples (Figure 2d) reveal that the aggregates are built from uniform nanoparticles. The rhodium sample shows almost non-aggregated nanoparticles (Figures 2e and 2f). The particle size distributions of metallic platinum, iridium and rhodium (Figure 3) were obtained from FE-SEM images by measuring the particle diameter of over 100 particles. The mean nanoparticle size was $9.2 \mathrm{~nm}$ for platinum, $21 \mathrm{~nm}$ for iridium, and $28 \mathrm{~nm}$ for rhodium. The average crystallite size of platinum nanoparticles estimated by the Scherrer equation is about $20 \%$ smaller than the mean particle size obtained from FE-SEM images. The results obtained by using the Scherrer equation tend to underestimate the crystallite size, because according to this method the broadening of diffraction lines is supposed to be solely the result of a small crystallite size. ${ }^{34}$ The close values of mean particle size and average crystallite size of platinum nanoparticles suggest that each of these particles consists of only one crystalline domain (crystallite). Unlike the case of platinum nanoparticles, the substantial difference in the mean particle size (observed by FE-SEM) and the average crystallite size 


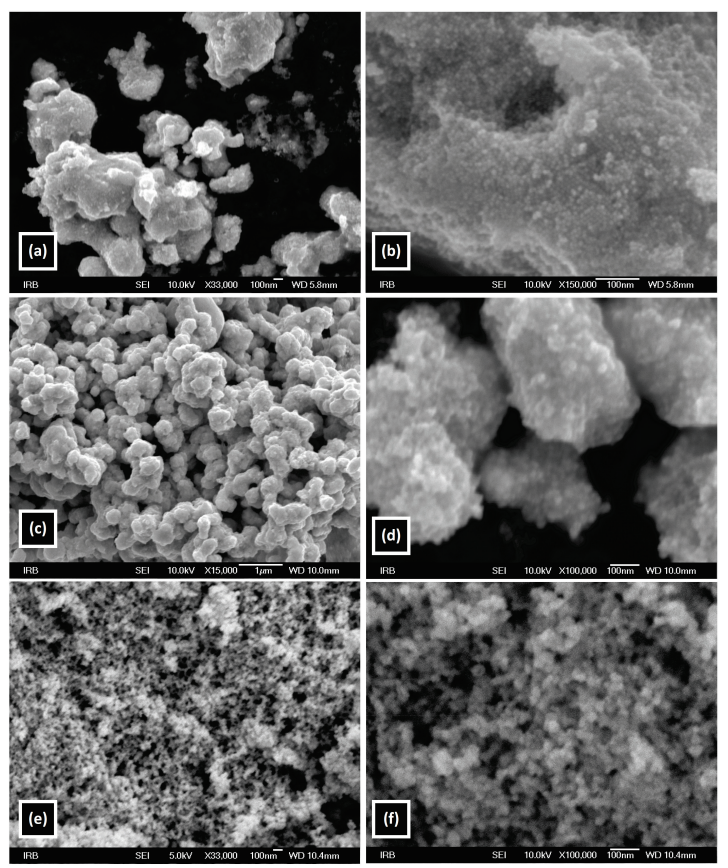

Figure 2. FE-SEM images of $(a, b)$ platinum nanoparticles, $(c, d)$ iridium nanoparticles, and (e, f) rhodium nanoparticles at lower and higher magnification, respectively

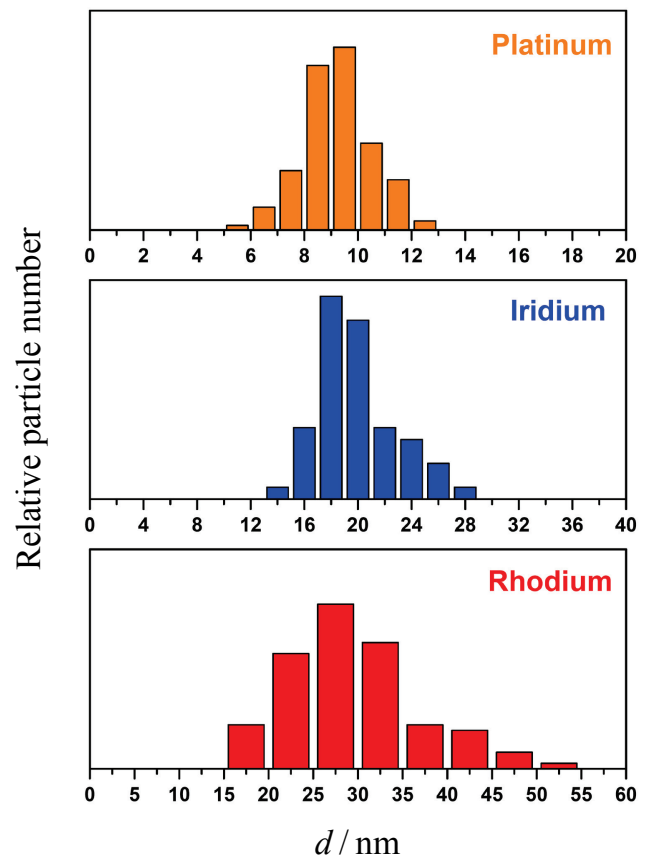

Figure 3. Size distributions of platinum, iridium and rhodium nanoparticles.

(determined by XRD) for iridium and rhodium samples suggests that these nanoparticles were formed by aggregation of even smaller particles. Formation of larger nanoparticles (28 and $21 \mathrm{~nm}$ ) consisting of small crystallites $(3.5$ and $3.1 \mathrm{~nm})$ in the case of rhodium and iridium can be explained by a higher aggregation potential of smaller crystallites with a large surface area (rhodium and iridium) in comparison with larger platinum crystallites $(7.4 \mathrm{~nm})$ with lower aggregation potential (smaller surface area) during the nanoparticles formation process.

In the present synthesis of platinum group metal nanoparticles TMAH has two functions: (a) as a strong alkali, which creates highly alkaline conditions for the formation of $\operatorname{Pt}(\mathrm{OH})_{4}, \operatorname{Ir}(\mathrm{OH})_{3}$ and $\mathrm{Rh}(\mathrm{OH})_{3}$ suspensions, and (b) as a source of methanol, which serves as a reducing agent for the reduction of metal ions. At the autoclaving temperature applied in this synthesis TMAH undergoes thermal decomposition yielding two principal products, trimethylamine and methanol. ${ }^{35,36}$ The methanol thus formed reduces $\operatorname{Pt}(\mathrm{IV}), \operatorname{Ir}(\mathrm{III})$ and $\mathrm{Rh}(\mathrm{III})$ in hydroxide suspensions creating conditions for nucleation of metallic platinum, iridium and rhodium particles. After a brief nucleation period nanoparticles continue to grow via addition of newly reduced atoms until unreduced species from the suspension have been depleted. Due to the formation of a lot of nuclei in the course of the brief nucleation step, the rest of material available for particle growth suffices only for the formation of tiny nanosize particles. In the case of platinum, the formed nanoparticles of $9.2 \mathrm{~nm}$ mean diameter were associated in irregular aggregates (Figure 2a). In the case of iridium and rhodium the primary nanoparticles (3-4 $\mathrm{nm}$ in size) were joined in the secondary nanoparticles of $21 \mathrm{~nm}$ mean size for iridium and $28 \mathrm{~nm}$ for rhodium. The secondary iridium nanoparticles were associated in uniform pseudospherical aggregates (Figure $2 \mathrm{c}$ ), whereas the secondary rhodium nanoparticles were unaggregated (Figures 2e and 2f).

Owing to the particle size and particularly strong reductive conditions created during the synthesis process, the platinum, iridium and rhodium nanoparticles thus formed are suitable for applications in catalytic reactions.

\section{REFERENCES}

1. N. N. Greenwood and A. Earnshaw, Chemistry of the Elements, $2^{\text {nd }}$ ed., Butterworth-Heinemann, Oxford, UK, 1997, pp. 1144 1172 .

2. S. A. Cotton, Chemistry of Precious metals, Blackie Academic, London, 1997, pp. 173-174.

3. P. J. Loferski, Platinum-group Metals, in: 2008 Minerals Yearbook, U.S. Geological Survey, 2010.

4. H. Bönnemann and K. S. Nagabhushana, Colloidal Nanoparticles in Catalysis, in: R. Richards (Ed.), Surface and Nanomolecular Catalysis, Taylor \& Francis, Boca Raton, 2006, p. 63.

5. C. Burda, X. Chen, R. Narayanan, and M. A. El-Sayed, Chem Rev. 105 (2005) 1025-1102.

6. A. Chen and P. Holt-Hindle, Chem. Rev. 110 (2010) 3767-3804.

7. T. S. Ahmadi, Z. L. Wang, T. C. Green, A. Henglein, and M. A. El-Sayed, Science 272 (1996) 1924-1926. 
8. J. M. Petroski, Z. L. Wang, T. C. Green, and M. A. El-Sayed, J. Phys. Chem. B 102 (1998) 3316-3320.

9. A. Miyazaki, I. Balint, and Y. Nakano, J. Nanopart. Res. 5 (2003) 69-80.

10. M. Hodos, Z. Kónya, G. Tasi, and I. Kiricsi, React. Kinet. Catal. Lett. 84 (2005) 341-350.

11. Z. Tang, D. Geng, and G. Lu, Mater. Lett. 59 (2005) 1567-1570.

12. C. W. Scheeren, G. Machado, S. R. Teixeira, J. Morais, J. B. Domingos, and J. Dupont, J. Phys. Chem. B 110 (2006) 1301113020

13. Z. Kónya, E. Molnar, G. Tasi, K. Niesz, G. A. Somorjai, and I. Kiricsi, Catal. Lett. 113 (2007) 19-28.

14. T. Teranishi, M. Hosoe, T. Tanaka, and M. Miyake, J. Phys. Chem. B 103 (1999) 3818-3827.

15. C.-W. Chen, D. Tano, and M. Akashi, J. Colloid Interface Sci. 225 (2000) 349-358

16. X. Mu, D. G. Evans, and Y. Kou, Catal. Lett. 97 (2004) 151-154.

17. M. Harada, D. Abe, and Y. Kimura, J. Colloid Interface Sci. 292 (2005) 119-121.

18. C.-S. Lin, M. R. Khan, and S. D. Lin, J. Colloid Interface Sci. 299 (2006) 678-685.

19. Z. Liu, M. Shamsuzzoha, E. T. Ada, W. M. Reichert, and D. E. Nikles, J. Power Sources 164 (2007) 472-480.

20. H. J. Salavagione, C. Sanchís, and E. Morallón, J. Phys. Chem. C 111 (2007) 12454-12460.

21. F. Bonet, V. Delmas, S. Grugeon, R. Herrera Urbina, P.-Y. Silvert, and K. Tekaia-Elhsissen, Nanostruct. Mater. 11 (1999) 1277-1284.

22. S. Chen and K. Kimura, J. Phys. Chem. B 105 (2001) 5397-5403.
23. J. Yang, T. C. Deivaraj, H.-P. Too, and J. Y. Lee, J. Phys. Chem. $B 108$ (2004) 2181-2185.

24. F. Şen and G. Gökağaç, J. Phys. Chem. C 111 (2007) 57155720.

25. A. Swami, A. Kumar, R. Pasricha, A. B. Mandale, and M. Sastry, J. Colloid Interface Sci. 271 (2004) 381-387.

26. C. Wang, H. Daimon, T. Onodera, T. Koda, and S. Sun, Angew. Chem. Int. Ed. 47 (2008) 3588 -3591.

27. S. Adora, Y. Soldo-Olivier, R. Faure, R. Durand, E. Dartyge, and F. Baudelet, J. Phys. Chem. B 105 (2001) 10489-10495.

28. M.-S. Löffler, B. Groß, H. Natter, R. Hempelmann, T. Krajewski, and J. Divisek, Scripta Mater. 44 (2001) 2253-2257.

29. F. Mafuné, J. Kohno, Y. Takeda, and T. Kondow, J. Phys. Chem. B 107 (2003) 4218-4223.

30. O. P. Yadav, A. Palmqvist, N. Cruise, and K. Holmberg, Colloid. Surface. A 221 (2003) 131-134.

31. O. Paschos, P. Choi, H. Efstathiadis, and P. Haldar, Thin Solid Films 516 (2008) 3796-3801.

32. C. W. Scheeren, G. Machado, S. R. Teixeira, J. Morais, J. B. Domingos, and J. Dupont, J. Phys. Chem. B 110 (2006) 1301113020 .

33. S. Krehula and S. Musić, Mater. Lett. 62 (2008) 4369-4370.

34. H. P. Klug and L. E. Alexander, X-Ray Diffraction Procedures for Polycrystalline and Amorphous Materials, $2^{\text {nd }}$ ed., Wiley, 1974, p. 687.

35. I. Tanczos, G. Pokol, J. Borsa, T. Tóth, and H. Schmidt, J. Anal. Appl. Pyrolysis 68-69 (2003) 173-185.

36. S. C. Moldoveanu, Analytical Pyrolysis of Synthetic Organic Polymers, Elsevier, Amsterdam, 2005, p. 52. 